JOSÉ LUÍS BRANDÃO FRANCISCO DE OLIVEIRA (COORD.)

IMPRENSA DA UNIVERSIDADE

DE COIMBRA

COIMBRA

UNIVERSITY

PRESS

\section{HISTÓRIA DE}
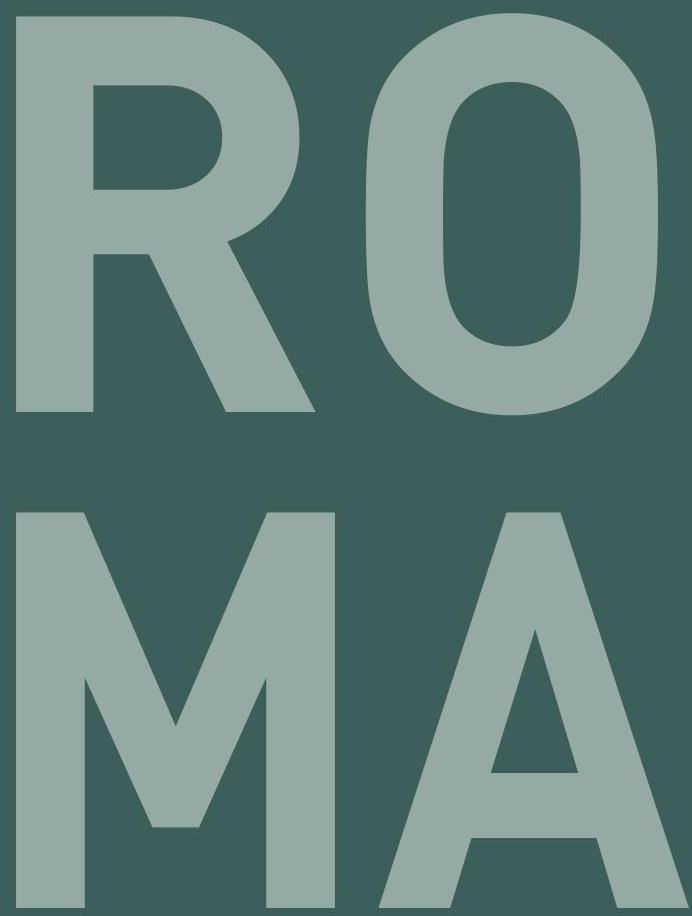

ANT

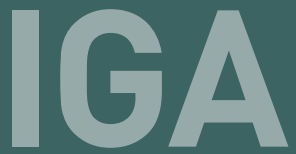

VOLUME II

IMPÉRIO ROMANO DO OCIDENTE E ROMANIDADE HISPÂNICA 


\title{
1. A diversidade linguística da Hispânia pré-romana
}

\author{
Amílcar Guerra \\ Faculdade de Letras de Lisboa \\ Centro de Arqueologia (UNIARQ) \\ Centro de História \\ ORCID: 0000-0003-3478-0036) \\ aguerra@campus.ul.pt
}

\begin{abstract}
Sumário: A Hispânia pré-romana apresenta-se culturalmente muito diversa, em certos aspetos mesmo contrastante. Essa multiplicidade cultural reflete-se igualmente no domínio linguístico. Ao invés de uma antiga tradição que postulava uma língua única originária, o quadro na altura da conquista apresenta uma compartimentação básica entre línguas indo-europeias (em que sobressaem o celtibérico e o lusitano) e as que não pertencem a este grupo (onde se destaca o ibérico). A realidade é, no entanto, mais complexa e as perspetivas sobre ela são muito diversas. Pretende-se dar conta, de uma forma necessariamente muito sintética, da evolução da investigação e do estado atual dos nossos conhecimentos neste domínio.
\end{abstract}

\section{Preâmbulo}

No processo de conquista e romanização da Hispânia por Roma, as fontes documentam um número muito amplo de povos, de cujas peculiaridades dão por vezes conta de forma mais ou menos circunstanciada. Esta componente étnica e a sua diversidade constitui um tópico frequente da historiografia, a qual tem procurado definir os territórios e as peculiaridades culturais de cada uma dessas distintas entidades. Naturalmente essa multiplicidade de povos tem os seus reflexos na vertente linguística, aspeto sobre o qual o nosso conhecimento, apesar de bastante limitado, tem progredido de forma substancial. A atenção que lhe tem sido dedicada nas últimas décadas, estimulada por algumas descobertas de importantes documentos que atestam algumas dessas línguas, 
permite-nos traçar um panorama que, embora inevitavelmente muito sintético, poderá ajudar a compreender uma faceta relevante das populaçóes que habitavam o extremo do mundo romano. Tratando-se de um conjunto de línguas de fragmentária atestação e em relação às quais varia de forma considerável o material que temos à disposição, o que se pode dizer a respeito de cada uma delas é também distinto.

Embora os últimos cinquenta anos tenham assistido a um substancial progresso neste domínio, as primeiras reflexōes importantes remontam já aos séc. XVIII e XIX, entre as quais cabe destacar a obra emblemática de Humboldt ${ }^{1}$, sobre cujas orientações gerais assentaram muitas das investigaçóes subsequentes. A um outro erudito alemão, Emil Hübner, conhecido especialmente pelo seu contributo para os volumes relativos à Hispânia e à Britânia do Corpus Inscriptionum Latinarum, se deve a primeira grande recolha sistemática da documentação respeitante à caracterização linguística da Península Ibérica em fase pré-romana. O título da obra, Monumenta Linguae Ibericae, revela-se muito sugestivo, por nele se patentear a ideia, dominante ao longo de muito tempo, de que em todo o espaço hispânico se registou uma relativa unidade no domínio da língua. $\mathrm{Na}$ realidade, o uso do singular não pressupunha que toda essa documentação era relativa a uma única realidade linguística, uma vez que se tornara patente, desde os primeiros estudos, a ocorrência de elementos externos, como os que manifestamente pertenciam a línguas célticas. A presença desses atribuía-se a movimentos populacionais, relativamente recentes, que se teriam sobreposto a uma realidade unitária, a língua ibérica.

A este postulado associava-se geralmente a ideia de que esta língua, originariamente estendida a todo o território hispânico, mas progressivamente circunscrita em especial às áreas meridional e levantina, teria continuidade no atual basco. Tratar-se-ia de uma língua não indo-europeia, de remota origem, que particulares circunstâncias de isolamento teriam permitido conservar até à atualidade.

A investigação desenvolvida ao longo do séc. XX veio questionar estes pressupostos, tanto o da unidade linguística primordial, como o da última teoria aludida, conhecida como "basco-iberismo".

O panorama da investigação atual caracteriza-se por reconhecer a diversidade do quadro linguístico no momento da conquista romana, materializada, desde logo, na dicotomia entre duas grandes áreas, consoante os seus vestígios pertencem ou não ao domínio indo-europeu. A sua mais conhecida formulação deve-se a Jürgen Untermann, que nos inícios da década de '60 do século passado utilizou a distribuição espacial de determinados elementos, com especial relevo para os de natureza toponímica (nomes em -briga, por um lado; em iltil iltur, ili, ilu por outro), para traçar uma linha separadora destes dois domínios ${ }^{2}$.

\footnotetext{
${ }^{1}$ A publicação inicial (Humboldt 1821) foi modernamente traduzida em espanhol (Humboldt 1990).

${ }^{2}$ Untermann 1962 15-17.
} 
O aprofundamento da análise, permitiu reconhecer, em cada uma delas, realidades diferenciadas, cuja caracterização varia muito consoante a sua natureza e a dimensão dos materiais que temos à disposição.

O objetivo deste contributo consiste precisamente em expor, de forma muito sintética, o estado atual dos conhecimentos a respeito de cada uma destas realidades, dando especial atenção às questôes que respeitam ao Ocidente peninsular, partindo da divisão básica enunciada por J. Untermann há algumas décadas entre um âmbito indo-europeu e outro que não se integra nesse domínio linguístico.

\section{Línguas não indo-europeias}

Dentro da vasta área que corresponde à faixa que se estende do sul da Península Ibérica pelo Levante e se larga por toda a zona pirenaica e área adjacente do sul de França têm-se considerado fundamentalmente duas realidades distintas, entre as quais se reconhecem, todavia, algumas afinidades: a língua ibérica e o antigo basco.

\section{1. $\mathrm{O}$ antigo basco}

A língua antecessora do basco moderno, atestada a partir da documentação medieval, reconstituída por investigadores como K. Mitxelena ${ }^{3}$, estender-se-ia por um território situado nas duas vertentes dos Pirenéus, ainda que não coincidente com a distribuição recente. Seria uma realidade linguística distinta da ibérica, não se afastando, todavia, a hipótese de haver uma influência mútua, dada a circunstância de terem estado em contacto na antiguidade. Desta forma se poderiam explicar algumas afinidades mais ou menos evidentes, mas que dariam fundamento a uma identidade entre elas.

A documentação pertinente ao basco antigo é bastante reduzida e reparte-se essencialmente por três áreas ${ }^{4}$ :

a) área aquitana, correspondente à vertente setentrional dos Pireneus Central e Ocidental. Proporciona essencialmente documentação onomástica pessoal $^{5}$, atestada na epigrafia latina, mas nada em escrita epicórica;

b) área meridional pirenaica: os vestígios são de uma maneira geral muito raros e problemáticos. Consistem essencialmente em elementos colhidos na toponímia, antroponímia e teonímia da área atribuída a Várdulos e

\footnotetext{
${ }^{3}$ Especialmente em Mitxelena 1961 ( $\left.{ }^{2} 1967\right)$.

${ }^{4}$ Para uma síntese recente das questôes relativas ao âmbito geográfico desta realidade v. Gorrochategui 2009 e também Velaza 2012 79-80.

${ }^{5}$ Constitui a obra de referência Gorrochategui 1984.
} 
Carístios, territórios nos quais, de qualquer modo, dominam os vestígios linguísticos indo-europeus;

c) região soriana dos vales do Cidacos e do Linares: alguns vestígios onomásticos se atestaram na epigrafia latina dessa área, cuja relação com o âmbito da antroponímia basco-aquitana se dá como segura e para cuja presença num espaço em que domina a antroponímia de origem celtibérica se têm aportado várias explicações - movimentos populacionais situáveis em período imperial romano; ou persistência de gentes num território em fase pré-romana pontualmente integrado no âmbito basco ${ }^{6}$.

Como se disse acima, um dos tópicos que marcou a investigação do passado até aos inícios do séc. XX, residia na convicção de que o basco era o representante moderno da língua ibérica, que em determinado momento tinha sido comum a toda a península, convivendo com outras línguas de invasores. Esta posição, no entanto, foi contestada em determinado momento, especialmente devido às novas perspetivas sobre as escritas e línguas da Península Ibérica devidas a Gómez Moreno, que sustentou e explicou a sua diversidade. A contestação atingiu um outro pressuposto: o de que a língua ibérica estava na origem do basco atual. Deste modo, em especial ao longo da segunda metade desse século, a antiga hipótese basco-iberista acabou por ser geralmente afastada e perdeu peso em âmbito académico.

Há cerca de uma década, todavia, a teoria basco-iberista foi retomada, reacendendo-se a discussão em torno desse tema algo adormecido. Uma das vertentes que tem estado na base desta renovada proposta (por isso às vezes designada neo-basco-iberista) reporta-se às formas que os numerais teriam assumido nas duas línguas, onde se verificariam tantas afinidades que dificilmente se poderia sustentar a hipótese de serem diferentes (v. infra).

\subsection{O ibérico ${ }^{7}$}

A língua ibérica apresenta-se-nos como indissociável de um conjunto de manifestações na escrita levantina, cujas manifestações se estendem da Alta Andaluzia ao Languedoc. No entanto, a mesma língua é igualmente transmitida por outros sistemas de escrita, nomeadamente pelas inscrições em alfabeto greco-ibérico e em escrita meridional ${ }^{8}$. Naturalmente, à documentação que nos foi transmitida por esta via tríplice deve acrescentar-se o material proporcionado pela epigrafia e numismática romanas, bem como pelos textos dos autores clássicos.

\footnotetext{
${ }^{6}$ v., mais recentemente, Gorrochategui 2009 545-546.

${ }^{7}$ Um recente e aprofundado estudo sobre a língua ibérica pode encontrar-se em de Hoz 2011a 221-360.

${ }^{8}$ De Hoz 2011a 23-24, 221.
} 
A extensão geográfica dos vestígios desta língua é, como se disse, bastante ampla. Em algumas regiôes desta vasta área documenta-se a convivência desta com outras línguas, sendo bem conhecido o caso do plurilinguismo documentado no sul de França'. Esta situação encontra-se na base de uma proposta de distinção, proposta por J. de Hoz, entre as áreas em que ela se se apresentaria como língua vernácula, que incluiria seguramente a Contestânia, mas que poderia estender-se a outras áreas adjacentes, talvez desde a Alta Andaluzia até um território que não ultrapassaria o rio Mijares ${ }^{10}$; e os outros âmbitos em que esta se assumiria como língua veicular ${ }^{11}$, isto é, em que ela não seria a língua vernácula, mas o instrumento de contacto no âmbito de comunidades plurilingues, sendo também a única que se apresentava sob uma forma escrita.

Apesar da abundante documentação relativa a esta língua, o que dela se conhece é muito limitado, em boa parte devido ao facto de não integrar o âmbito indo-europeu. As dificuldades começam com as questôes de fonética e fonologia do ibérico ${ }^{12}$. Verifica-se algum consenso a respeito do sistema fonológico, nomeadamente quanto à existência de cinco vogais $(a, e, i, o, u)$ ou das oclusivas, tanto surdas $(t, k)$ como sonoras $(b, d, g)$; mas é discutida a presença das semivogais $y$ e $w$ e também se hesita quanto ao número de sibilantes, vibrantes e nasais. Persiste, para além disso, uma incerteza a respeito do valor fonético do signo $\mathrm{Y}$.

No que concerne aos aspetos morfológicos o nosso conhecimento é reduzido $^{13}$. É possível, desde logo, identificar um conjunto assinalável de segmentos, cuja natureza e significado são geralmente difíceis de estabelecer, sendo por isso classificados com o termo neutro de morfos, maioritariamente sufixos, mas também prefixos e infixos. De uma forma geral estes assumem-se como integrando as formações nominais, ainda que pontualmente se tenham sugerido a sua presença em formas verbais.

Mas o aspeto mais amplamente desenvolvido da formação de palavras tem que ver com a estrutura dos nomes pessoais ${ }^{14}$, em relação aos quais são mais abundantes e claros os dados, em particular graças ao contributo inestimável da inscrição do Bronze de Ascoli (CIL I 709; CIL VI 37045). A estrutura canónica dos antropónimos ibéricos aí registados consiste numa justaposição de dois membros, geralmente dissilábicos, ainda que não faltem exemplos de

\footnotetext{
${ }^{9}$ Untermann 1964 .
}

${ }^{10}$ De Hoz 2009 427; 2011 b 33-36.

${ }^{11}$ De Hoz 2009; 2011 a 443-446; 2011 b.

${ }^{12}$ Sobre esta vertente da língua v. Correa, 1994 268-279; Velaza, 1996 40-43; Quintanilla 1998; de Hoz 2001 337-340; 2011a 223-257.

${ }^{13}$ Para uma perspetiva geral sobre a morfologia do ibérico v. MLH III 509-543; Velaza 1996 4452; de Hoz, 2001, 340-349; Rodríguez Ramos 2002 333-344; Orduña 2006; de Hoz 2011a 257-282.

${ }^{14}$ Uma recente e ampla análise desta vertente pode ver-se em de Hoz 2011a 324-338. 
monossílabos. Constata-se, além disso, que esses constituintes podem mudar de posição, ocorrendo indistintamente como primeiro ou segundo elemento dos nomes. Assim, por exemplo, em Illurtibas Bilustibas f(ilius) reconhece-se o elemento -tibas, permitindo definir também illur e bilus.

No que se refere à sintaxe e ao léxico o nosso conhecimento é mais precário. Neste último domínio registam-se algumas propostas de interpretação sobre o significado de alguns termos que ocorrem com certa frequência em determinados contextos, a respeito dos quais se produziram conjeturas mais ou menos viáveis. Talvez uma das mais consagradas referências diga respeito ao elemento ilti(ŕ)/iltu(r)/iltun/ilu(n), registado numa ampla série de topónimos como iltiŕta (lat. Ilerda), ilturo (Iluro), Illurco, Illugo, e que se relacionou com o antigo basco ili/iri, com o significado de "cidade" 15 . Este, tal como outros casos, foram objeto de discussão no âmbito dos especialistas, sem que se tivesse identificado alguma situação não controversa ou duvidosa.

Por fim, a questão dos numerais ibéricos tem sido objeto, especialmente nos últimos anos, de importantes considerações. Recolhendo e ampliando algumas sugestōes anteriores, E. Orduña apresentou um primeiro quadro de numerais ${ }^{16}$, proposta que foi ampliada em alguns trabalhos posteriores sobre o mesmo tema ${ }^{17}$. Estes contributos, para além de apoiarem a identificação de sequências correspondentes a números, sublinharam a afinidade que estes evidenciavam com os seus equivalentes basco, coincidência que foi interpretada de diferentes modos: por um lado, poderia resultar de um empréstimo, segundo a interpretação em determinado momento sustentada por Orduña ${ }^{18}$; por outro, seria consequência de relação genética entre ambas, hipótese que se consolidou em trabalhos posteriores ${ }^{19}$.

Sem se rejeitarem as inegáveis afinidades entre estas primitivas línguas hispânicas, a aceitação da relação genética entre ibérico e antigo basco está longe de ser pacífica ${ }^{20}$.

Enfim, o ibérico constitui uma realidade que oferece um conjunto documental bastante largo, mas que coloca problemas muito complexos em relação aos quais a investigação vai construindo interpretações em que o consenso é difícil. À margem disso, constitui também um campo fértil para as mais inacreditáveis propostas, aparecendo esporadicamente aventureiros que propalam anúncios de decifração sem consistência.

${ }^{15}$ MLH III.1 188. Sobre a possibilidade de existir uma outra raiz similar, com valor hidronímico v. de $\mathrm{Hoz} 2011$ a 316.

\footnotetext{
${ }^{16}$ Orduña 2005.

${ }^{17}$ Ferrer i Jané 2009; Orduña 2011.

${ }^{18}$ Orduña 2005.

${ }^{19}$ Ferrer i Jané 2009 471; Orduña 2011 129-130, 137-138.

${ }^{20}$ De Hoz, 2009; 2011a 196-198; Lakarra 2010.
} 


\subsection{Língua(s) do âmbito meridional ${ }^{21}$}

A especificidade linguística em período pré-romano da área meridional da Península Ibérica, correspondente genericamente à Andaluzia ocidental e ao extremo sul de Portugal, foi reconhecida inicialmente por Gómez Moreno. A partir da identificação de sistemas de uma escrita característica desta área, que designou como bástulo-turdetana, definiu alguns nomes característicos dessa região meridional, em particular a série de topónimos em ipo, a par de uba, urci, tuci, ucci, murgi, ici, estabelecendo a diferenciação onomástica entre esta região ("tartéssica”) e a ibérica ${ }^{22}$.

Tal como ele, também Tovar assinalou, de qualquer modo, afinidades entre alguns topónimos desta área e outros que poderiam ser bascos ou ibéricos. Entre estes poderiam estar nomes como Ilurco ou Iliturgi, nos quais reconheceu o elemento ili-, bem documento e característico da toponímia ibérica, recordando ao mesmo tempo uma proposta de Schulten segundo a qual o antigo nome do rio Odiel, Urius, remontaria ao basco ur- "água"23. Estes autores partilham a ideia de que as diferenças assinaladas podem não implicar uma língua diferente, mas constituir-se como dialetos variados no contexto do ibérico.

No entanto, a tendência que se afirmou progressivamente foi a de considerar que, para além de nessa região se identificarem elementos linguísticos de origem variada (fenício-púnica, ibérica, céltica, etc.), regista-se uma componente onomástica (especialmente toponímica e antroponímica) que pode considerar-se distinta, nem indo-europeia nem ibérica, cuja associação com o mundo tartéssico / turdetano se considera mais ou menos inequívoca ${ }^{24}$. Um dos problemas que se colocou tinha que ver com a extensão territorial destes particularismos e em consequência da língua a que pertenciam. Ganhava especial acuidade o facto de os nomes em -ipo, longe de se limitarem à Andaluzia ocidental, estendiam-se pelo sul e centro de Portugal, tendo como exemplo mais setentrional Collipo, cidade que se situaria em S. Sebastião do Freixo, Batalha. Já Gómez Moreno ${ }^{25}$ tinha avançado com a hipótese de estes nomes, dispersos pelas costas ocidentais da Hispânia, poderem resultar de um processo de colonização tartéssica, não implicando, portanto, que em toda a região se tivesse falado a língua dos colonizadores.

Outra questão que se colocou diz respeito à relação que poderia existir entre esta língua e a das inscrições na escrita pré-romana do Sudoeste peninsular que alguns designam como tartéssica, a qual não tem tido uma resposta

\footnotetext{
${ }^{21}$ Para este tópico v. Villar 2000 e, mais recentemente, de Hoz 2010 386-402, 455-478.

${ }^{22}$ Gómez Moreno 1949203.

${ }^{23}$ Tovar 1961114.

${ }^{24}$ Correa 2009a 295-298; de Hoz 2010 455-478, esp. 471-472.

${ }^{25} 1949202-203$.
} 
unívoca, dadas as dificuldades que se colocam à caracterização de cada uma das realidades comparadas. O reduzido número de textos, muito deles fragmentários, as incertezas quanto ao valor de alguns signos, a quase total ausência de separação das palavras são fatores que acentuam as dificuldades de caracterização da língua transcrita por esse conjunto de monumentos epigráficos, maioritariamente constituído por estelas funerárias. A investigação, desenvolvida especialmente no último meio século, tem hesitado especialmente entre duas possibilidades: considerar que nestas se transmite uma língua local não indo-europei ${ }^{26}$, que poderia relacionar-se com as realidades identificadas neste âmbito tartéssico-turdetano ${ }^{27}$ ou ser uma realidade distinta ${ }^{28}$; ou aceitar que se trata de língua indo-europeia, para alguns integrada no âmbito céltico ${ }^{29}$, de que se poderiam identificar algumas sequências, essencialmente antropónimos, mas também outros elementos a que poderia ser atribuída essa origem ${ }^{30}$.

As limitaçõos inerentes à documentação, atrás referidas de forma sumária, não permitem resolver de forma satisfatória este problema, pelo que se mantém tradicionalmente uma posição de reserva sobre ele, mesmo quanto se partilham determinadas ideias sobre a natureza das populações a que estas manifestações se encontram associadas.

\section{As línguas indo-europeias}

\subsection{Celtibérico}

Num quadro geral dominado pelas incertezas e pela falta de dados que permitam a adequada caracterização das diferentes línguas hispânicas, o celtibérico constitui-se como um caso particular. Pela sua natureza, pela dimensão e variedade da documentação que lhe diz respeito, constitui a mais bem conhecida das línguas pré-romanas da Hispânia. Trata-se de uma língua indo-europeia, cuja integração no grupo céltico não oferece dúvidas.

Encontra-se atestada por um conjunto diversificado de documentos, sobrelevando as inscrições em escrita epicórica, alguns bastante extensos, entre os quais se destacam, pela sua dimensão e importância, os textos gravados nos bronzes

\footnotetext{
${ }^{26}$ Correa 1996 72-73; Rodríguez Ramos 2002 90-91; de Hoz 2010402.

${ }^{27}$ Para esta perspetiva v. mais recentemente Correa 2009a esp. 296-297.

${ }^{28}$ Rodríguez Ramos 2002, 90-91; de Hoz 2010 400-402.

${ }^{29}$ Podem encontrar-se argumentos a favor desta hipótese em Wikander 1966, Correa 1985391 -392; 1992 98-102; MLH IV 165; Villar 2000; Rodríguez Ramos 2002 89-91. Mais recentemente Koch (2009; 2011 esp. 43-100), para além de sustentar a natureza céltica da língua plasmada nestes textos epigráficos, propôs traduçōes para alguns deles.

${ }^{30}$ Correa 1989; MLH IV 167-168. De uma forma algo mais restritiva de Hoz 2010, 394-396, 400-401.
} 
encontrados em Botorrita, em particular o que é conhecido como Botorrita III. Naturalmente, também os textos clássicos gregos e latinos e a epigrafia romana aportam um conjunto substancial de elementos respeitantes a esta mesma realidade, mas especialmente centrados no domínio da onomástica pessoal ou de natureza geográfica. Para além disso, assumem igualmente considerável importância as abundantes legendas monetárias, uma parte em escrita epicórica.

A natureza da documentação, em especial um conjunto considerável de textos longos (de natureza jurídica?) faz que o repositório desta língua seja mais variado que em outras realidades similares, cujo conhecimento se encontra fortemente condicionado pela excessiva dependência de nomes próprios e a escassa presença de léxico comum.

O celtibérico fala-se, desde logo, na Celtibéria antiga, tal como a definem alguns autores clássicos, a qual engloba, desde logo, belos, títios, lusões e arévacos, mas onde ocasionalmente algumas fontes integram também pelêndones e vaceus. Mas o seu âmbito espacial estende-se genericamente por toda área em que se atestam as inscriçôes na escrita epicórica, na qual se integram, para além destes, pelos menos os beróes. Do ponto de vista geográfico, corresponde a um território genericamente limitado pelo curso médio do rio Ebro e que engloba as bacias superiores do Douro, Tejo, Júcar e Túria.

Embora o celtibérico se inclua no âmbito das línguas de fragmentária atestação, os elementos de que dispomos permitem enunciar um conjunto significativo de particularidades, tanto no domínio fonético, como no morfológico e lexical ${ }^{31}$.

No que respeita às peculiaridades fonéticas, uma das mais marcantes, que a distingue, por exemplo, do lusitano e que constitui uma das marcas da sua integração no grupo céltico é a perda do ${ }^{*} p$ inicial ou intervocálico, como se pode verificar, por exemplo no topónimo letisama, cujo elemento inicial remonta a *pleth- "amplo".

No domínio da morfologia, a informação de que dispomos, se comparada com realidades similares da Hispânia, pode considerar-se substancial, em especial no que diz respeito à flexão nominal. O celtibérico possuía seis casos: nominativo, acusativo, genitivo, dativo, ablativo / instrumental e locativo. Dispomos de informação bastante completa no que respeita às desinências do singular, em particular para os temas em $-\bar{a} /-\partial,-\breve{o},-\breve{\imath}$ e para a maior parte dos temas em consoante. No que concerne ao plural, os dados apresentam bastantes lacunas, à exceção do tema em -o, em relação à qual a documentação é completa.

Quanto aos adjetivos, cuja flexão se liga à dos nomes, destaca-se o nosso conhecimento respeitante ao processo de formação e à expressão dos graus. São abundantes os exemplos de formaçôes adjetivais, em particular as que têm como base topónimos e, em menor grau, etnónimos ou antropónimos. Destaca-se, neste domínio, a abundância dos derivados com sufixo em $-k o$, que constituem

${ }^{31}$ Sobre o celtibério v. essencialmente Jordán 2004, obra para a qual se remete para todas as questôes a seguir tratadas. 
uma parte substancial do repositório. Ocorrem especialmente em legendas monetárias ou em tésseras em escrita epicórica, podendo citar-se, a título de exemplo, casos como arekoratika (de arekorata), sekontiaka (de sekontios), uirouiaka (de uirouia). No caso de derivados antroponímicos são especialmente conhecidos os nomes de grupos familiares, como albinokum (de Albinus), tirtanikum (de tirtanos), turanikum (de Turanus), elemento característico da identificação pessoal dessa área.

No que respeita à gradação, é especialmente conhecida a formação de superlativo, já identificada por Tovar numa conhecida inscrição de Peñalba de Villastar onde se lê TVROS CAROQVM VIROS VERAMOS. Este erudito tinha justamente reconhecido, em * uper-mmo- a origem de VERAMOS, tal como usama resultava de ${ }^{*} u p s-m m a$.

O panorama é substancialmente diferente no que toca à flexão verbal sobre a qual dispomos apenas de escassos elementos, em particular algumas de $3 .^{a}$ pessoa sing. em - $t i$, mas também em $-t$, bem como de 3 . $^{a}$ pessoa pl. em $-n t i$ e $-n t$, na ativa e -nto na voz média. Também se identificaram formas de imperativo futuro, terminadas em -tuz, que remontam a -tođ < -tod, com paralelos em vários línguas indo-europeias. Ainda que se encontrem identificadas mais algumas particularidades da flexão verbal, na globalidade pode dizer-se que o conhecimento se limita a alguns aspetos isolados no contexto de uma realidade muito complexa.

Uma situação similar é partilhada pelos pronomes, advérbios, conjunções e preposições, que fornecem um panorama bastante fragmentário, mas em relação ao qual se podem apresentar alguns exemplos do sucesso da investigação neste domínio. No que concerne aos pronomes podem referir-se dois casos com maior substância: alguns demonstrativos, em particular sa (nom. sing.), saum (gen. pl. fem.), so (nom. ou gen. sing. masc.) somei (loc. sing.) e provavelmente também soz, cuja integração flexional se discute; e os relativos, que se consideram documentados pelo menos em ias (nom. pl. fem.), ia (?), ios (nom. sing. masc.), iomui (dat. sing. masc. ou neut.) e iosum (gen. pl. masc.). No que concerne às conjunções, sublinhe-se a atestação da copulativa enclítica -kue, com paralelos, por exemplo, no latim -que e no grego te.

No que respeita ao léxico, evidencia-se um claro desequilíbrio quanto à relação entre nomes próprios e comuns. A natureza da documentação - o facto de contarmos com uma informação que resulta em boa parte dos textos literários gregos e latinos, da epigrafia latina e da numismática, tanto em escrita epicórica como em latim - faz que com uma parte substancial dos nomes cuja natureza se conhece corresponda a antropónimos, etnónimos e topónimos. De qualquer modo, destacam-se alguns domínios do léxico comum, em particular alguns termos que exprimem as relações de parentesco: os que se associam à expressão do patronímico, seguindo uma tradição latina, equivalente a filius, kentis, e filia, atestado sob as formas tuateros e tuateres. que se pode aproximar do gr. thugater. A este mesmo âmbito parece pertencer o termo launi, de significado mais controverso, que Untermann relaciona hipoteticamente com "esposa”. 
$\mathrm{Na}$ realidade, o nosso reduzido conhecimento da língua e, em consequência, do sentido dos textos mais complexos, limita muito a explicação etimológica de muitos termos. De qualquer modo, a proximidade do celtibérico com outras línguas célticas torna credíveis algumas interpretações. Por exemplo, o elemento que em latim ocorre sob a forma -briga, regista-se em nomes como nertobis ou sekobirikez, neste último caso associado a outro bem conhecido, * ${ }^{\text {sego }}$ "vitória". Estas circunstâncias, todavia, não ocorrem com frequência e para um bom número de termos não encontrou ainda uma interpretação segura. Trata-se, naturalmente, de um território complexo, sujeito a especulação e à controvérsia.

Discute-se, enfim, a eventualidade de se incluírem no celtibérico algumas realidades adjacentes, nomeadamente as que se relacionam com o território vaceu ou as que se associam aos cântabros. Os vestígios dos falares pré-romanos destas regiōes são muito restritos e não permitem responder de forma categórica a esta questão.

\subsection{Língua(s) do Ocidente hispânico}

No quadro do Ocidente hispânico a tradição estabeleceu uma diversidade linguística em função das grandes entidades étnicas, a saber, Galaicos, Ástures, Vetōes, Lusitanos. Coube a Tovar a caracterização da língua atribuída aos últimos, que por isso mesmo designou como "lusitano", termo generalizado, mas não isento de problemas. Trata-se de uma língua indo-europeia pré-romana falada no extremo ocidente peninsular, no território que tradicionalmente e segundo a formulação inicial de A. Tovar corresponderia genericamente ao da área de distribuição de um pequeno conjunto de inscriçōes em escrita latina, sensivelmente compreendida entre o curso do rio Douro a norte e, seguindo uma proposta de Albertos baseada na análise antroponímica, uma linha que ligaria Badajoz a Setúbal. A questão dos limites da língua lusitana está longe de ser encerrada, devendo manter-se em aberto a possibilidade de ela se estender a territórios onde não se identificaram inscrições nessa língua, todas em escrita latina.

$\mathrm{Na}$ realidade, a documentação pertinente a esta realidade é bastante pobre. Contamos essencialmente com um amplo repertório onomástico, constituído em especial por antropónimos, nomes de natureza geográfica e teónimos, atestados de modo particular na epigrafia latina e também nos textos clássicos gregos e latinos. É especialmente reduzido o número de inscrições nessa língua, uma vez que não ultrapassa os seis exemplares, metade (se considerarmos separadamente os dois mais antigos) proveniente de um mesmo sítio, a localidade chamada em tempos Arroyo del Puerco (atualmente Arroyo de la Luz), na província de Cáceres. Outras três procedem de território português: uma, há muito conhecida, de Lamas de Moledo (Castro Daire); outra, achada recentemente nas proximidades de Arronches; e, por fim, um dos documentos 
fundamentais, divulgado por Adriano Vasco Rodrigues ${ }^{32}$, uma inscrição rupestre subsistente no topo do Cabeço das Fráguas, um lugar remoto nos limites dos concelhos da Guarda e do Sabugal.

A relevância desta última decorre do facto de ter estado na base da primeira caracterização da língua lusitana, devida a $\mathrm{A}$. Tovar ${ }^{33}$. A gravação do texto é profunda, pelo que a sua leitura é geralmente clara e quase consensual. A única divergência regista-se na lição de LAEBO, para a qual J. Untermann propôs $\mathrm{LABBO}^{34}$.

$\mathrm{Na}$ interpretação do linguista espanhol esta epígrafe reportava um sacrifício múltiplo, em que um conjunto de animais - ovelha, porco, comaia e touro - era oferecido a uma série de divindades, Trebopala, Labbo (Laebo, na sua versão), Iccona Loimina, Trebaruna e Reve.

O sentido que Tovar conferiu ao texto do Cabeço das Fráguas abriu caminho à interpretação da epígrafe de Lamas de Moledo ${ }^{35}$, na qual se reconheceu uma estrutura similar, em que as vítimas sacrificiais alternavam com as divindades a que eram oferecidas, embora com algumas dificuldades pontuais na lição de alguns nomes e na interpretação do texto.

Mais recentemente registou-se um importante achado na região de Arronches ${ }^{36}$, cuja primeira parte patenteia uma estrutura semelhante e na qual um repertório mais extenso de vítimas recorda elementos documentados nas restantes inscrições conhecidas: oilam erbam (erbae em Arroyo de la Luz); oila $X$; taur [o] ifate $X$ (remetendo para taurom ifadem do Cabeço das Fráguas); e a sequência $A V[---]$, a permitir uma eventual comparação com o nome do animal registado em Lamas de Moledo, habitualmente interpretado como ancom.

Como é mais natural uma repetição do nome das vítimas que o das divindades, mais diversificadas e dependentes das diferenças regionais, o quadro dos teónimos não coincide com o das outras inscrições, mas enquadra-se perfeitamente no que se conhece: Harase, Broeneiae, Reve Aharacui, Bandi Haracui, Munitie Carla Cantibidone. De todos eles apenas o segundo, Broeneiae, é completamente novo no quadro dos nomes de divindade.

Com base nesta documentação, pôde constatar-se que um dos traços mais marcantes da língua lusitana, que a distingue, por exemplo, do celtibérico, é a

\footnotetext{
$321959-6071-73$.
}

${ }^{33} \mathrm{O}$ estudo inicial da inscrição (Tovar 1966-67) foi atualizado em Tovar 1985. Propostas interpretativas posteriores em Untermann 1987 63-64; MLH IV L.3.1; Búa 1999 317-326; Untermann 2002 69-70; Prósper 2002 41-56; Ribeiro 2013 esp. 238-240.

${ }^{34}$ Nela se leria, segundo a proposta de Untermann (MLH IV L.3): OILAM TREBOPALA INDI PORCOM LABBO COMAIAM ICCONA LOIMINA OILAM VSSEAM TREBARVNE INDI TAVROM IFADEM REVE TRE[---].

${ }^{35}$ Distintas interpretações posteriores em Untermann 1987 64-66; Curado 1989 351-353; Búa 1999 321-326; Prósper 200257-68.

${ }^{36}$ Sobre as diferentes leituras e interpretaçōes desta inscrição v. Carneiro et alii 2008; Prósper - Villar 2009; Ribeiro, 2010. 
conservação do ${ }^{*} p$, como se torna manifesto no exemplo clássico de porcom. Dado que uma das outras peculiaridades é a tendência para a sonorização das oclusivas $^{37}$, não surpreende que se registem casos Bletisama, no qual o grupo * $p l$ - evolui para $b l$-. De resto, a informação desta vertente da língua é particularmente reduzida e problemática e, por isso, não é fácil definir alguns traços caracterizadores da língua lusitana. Entre estes se tem considerado a perda da aspiração na série sonora aspirada proto indo-europeia $\left({ }^{*} b^{h},{ }^{*} d^{h},{ }^{*} g^{h} \mathrm{e}{ }^{*} g^{w h}>{ }^{*} b\right.$, ${ }^{*} d,{ }^{*} g$ e ${ }^{*} g^{w}$ respetivamente) que a teonímia e antroponímia parecem confirmar ${ }^{38}$. Aparentemente, os dados de que dispomos parecem um pouco mais claros no domínio morfológico, em particular no que toca a algumas particularidades flexionais dos nomes. $\mathrm{O}$ acus. sing. apresenta genericamente a desinência - $m$, como se podem verificar nos diferentes temas, através de exemplos oilam e taurom ifadem, recolhidos na inscrição do Cabeço das Fráguas.

O dativo parece apresentar, na flexão nominal temática, a desinência $-i$ : deste modo, ocorre nos temas em -a como - ai (Crongeai, Ioveai), e nos temas em -o como -oi ou suas variantes gráficas - $u i$, -oe, por exemplo em Caeilobricoi ou Macareaicoi - todos exemplos retirados da epígrafe rupestre de Lamas de Moledo. Note-se que vestígios desta flexão revelam uma tendência para a perduração na epigrafia latina, de modo particular nas dedicatórias votivas, como a de Reve Langanidaeigui (AE 1961, 353, de Medelim, Idanha-a-Nova).

$\mathrm{Na}$ perspetiva de A. Tovar, a inscrição do Cabeço das Fráguas documentava uma forma peculiar de dativo, em - $a$, correspondente à sequência Iccona Loimina. Esta interpretação não foi, contudo, seguida por muitos investigadores, que propuseram interpretaçôes muito diversificadas, mas também elas pouco consensuais. Untermann ${ }^{39}$, na sequência de Maggi e de Best, considera Trebopala e Iccona Loimina nominativos, caso em que estaria igualmente Labbo, todos correspondentes a sujeitos de um verbo omitido, com o significado de "sacrificar". C. Búa ${ }^{40}$ questiona igualmente a interpretação tradicional dos mesmos nomes, que interpreta como "complementos no concertados" referentes a lugares. Mais recentemente, J. Cardim Ribeiro assume todos os nomes tradicionalmente considerados teónimos (Trebopala, Labbo, Iccona Loimina, Trebarune e Reve) como vocativos ${ }^{41}$.

${ }^{37}$ Esta particularidade, bem atestada, ocorre especialmente em posição interior, mas não se regista de uma forma sistemática (Vallejo 2005 282).

${ }^{38}$ Búa 2000 167-168; Vallejo 2005 708; 2013 278-280.

${ }^{39}$ Ultimamente, em Untermann 2002 69-70, onde propõe a tradução seguinte: "A guarda do santuário (tem que sacrificar) uma ovelha e depois um porco; a (ou o) labbo (sacrifica) uma commaia (uma espécie de cabra?); a iccona loimina sacrifica uma ovelha de alta qualidade à deusa Trebaruna e depois um touro (...) a Reve ...".

$401999320-326$.

${ }^{41} 2013$ 239-243, pelo que a inscrição, na sua interpretação, diria: '(Damos-te) esta ovelha, ó Trebopala, e (damos-te) este porco, ó Labbo! (Damos-te) esta commaia, ó Iccona Loiminna! (Damos-te) esta ovelha ussea, ó Trebarune, e (damos-te) este touro consagrado, ó Reve Tre[...]. 
A questão é complexa e, como se vê, sem solução consensual. É patente que formas como Trebopala, Iccona Loimina ou Labbo não possuem as desinências habituais do dativo lusitano, o que, no plano dos princípios, dá consistência às alternativas propostas à interpretação tradicional. Esta, por sua vez, assenta na existência de alguns casos excecionais de dativos em - a em documentação epigráfica latina, como a que ocorre na dedicatória a divindades indígenas Arant[i]a Ocela[e]ca et A[r]antio [O]celaeco (RAP 11 de Ferro, Covilhã).

Encontra-se, para além disso, bem atestado o dativo em -e (que respeitaria aos temas em - $i$ ou consoante), documentado em especial no teónimo Reve ou em Trebarune (Triborunni na inscrição de Freiria, Cascais).

A identificação de plurais é bastante limitada. Mesmo assim, Veaminicori tem-se interpretado como nominativo do tema em -o e, mais recentemente, a inscrição de Arronches contribui para o repertório com alguns acusativos: oila e ifate, em ambos caso seguidos do que interpreta como o numeral latino X, o que parece confirmar uma tendência à perda o $-s$ final, que se documentaria igualmente no dat. plural, em - bo em todos os temas, a julgar pelas sequências Deibabo Nemucelaecabo (Avelelas, Chaves) e Arabo Corobelicobo Talasicobo (Arroyomolinos de la Vera, Cáceres) ${ }^{42}$. No entanto, o recente exemplo originário da área tradicionalmente integrada no âmbito lusitano, a dedicatória Deibabor igo Deibobor Vissaieigobor, proveniente de Viseu, veio chamar a atenção para algumas variaçôes flexionais no Ocidente ${ }^{43}$. Neste caso, dar-se-ia o fenómeno de rotacionismo do $-s$, ao contrário do que sucede em todas as outras atestações similares, em que este último se perde.

Registe-se, como outra marca característica, a partícula copulativa indi $\left(<{ }^{*} n\right.$-dhi), atestada tanto nas Fráguas como em Arroyo de la Luz e que revelaria um particular tratamento das nasais no lusitano ${ }^{44}$.

A. Tovar sustentara que o sacrifício documentado nesta inscrição, ao incluir um touro, uma ovelha e um porco, recordaria os célebres rituais romanos onde estes mesmos animais se ofereciam, os suovetaurilia ${ }^{45}$, procurando com isso sublinhar a existência de um fundo cultural comum, que radicaria na circunstância de também o lusitano ser uma língua indo-europeia.

Para além dessa integração linguística genérica, Tovar sustentou que o lusitano se deveria considerar autónomo de qualquer dos grupos conhecidos,

\footnotetext{
${ }^{42}$ Búa 1997 60-61.

${ }^{43}$ Fernandes - Carvalho - Figueira 2009 146; Vallejo 2013.

${ }^{44}$ Tovar 1985 238-239.
}

${ }^{45}$ Tovar 1985 245-247. Apesar de se repetirem alguns dos animais sacrificados, esta aproximação aos suovetaurilia é algo forçada. Na realidade, não se verifica uma verdadeira coincidência com esse sacrifício romano, tendo em consideração que, para além de se apresentarem duas ovelhas, há ainda um outro animal (comaiam), de identidade desconhecida, que se inclui no sacrifício. De resto, a circunstância de se oferecerem bois, ovelhas e porcos deve considerar-se habitual, dada a realidade da domesticação neste período, sem que a oferenda destes signifique uma identidade de ritos e tradições culturais. 
afastando especialmente a hipótese da sua integração no âmbito das línguas célticas. Esta postura assenta essencialmente em duas particularidades acima referidas: a circunstância decisiva de nela se manter o ${ }^{*} p$ - etimológico em posição inicial, como o demonstrava a palavra porcom; e o facto de apresentar a partícula copulativa indi.

Embora uma grande maioria dos investigadores partilhem a posição do Tovar, adicionando-lhe pontualmente mais alguns argumentos, J. Untermann ${ }^{46}$ sustentou que, dadas as grandes afinidades que se manifestam entre o lusitano e as línguas célticas, se deveria admitir a possibilidade de o lusitano ser uma língua desse grupo, do qual teria divergido antes que a perda do ${ }^{*} p$ - se tivesse dado.

O termo "lusitano", criado por Tovar e aceite pela generalidade dos investigadores, pressupunha que uma série de línguas no Ocidente hispânico, ainda que apresentando afinidades com ela, se deveriam diferenciar. Neste caso se encontrava o falar dos Galaicos, a que ele próprio dedicou um estudo ${ }^{47}$. A falta de inscrições na língua pré-romana local limita a demarcação de particularidades a alguns teónimos e antropónimos, dados que, no seu conjunto, são pouco significativos.

A respeito desta área levantou-se igualmente uma outra questão relativa à eventual coexistência entre o galaico e uma língua céltica, diferenciada dele. Esta perspetiva assentaria num conjunto de particularidades a que pertenceriam, por exemplo, os característicos nomes em -briga, especialmente abundantes na região e receberia apoio das informaçôes dos autores clássicos que aí identificam um conjunto de entidades designadas como "célticas" 48 .

Esta ideia de uma multiplicidade linguística contrasta com a visão de Untermann, para o qual todos estes elementos pertencem a uma única língua, integrável no grupo céltico ${ }^{49}$. De facto, a amplitude dos elementos comuns patentes desde logo na toponímia, na antroponímia e nos bem característicos teónimos - alimentou a convicção de que estes povos teriam usado uma língua comum. C. Búa materializou esta ideia, ao cunhar o termo "hispânico ocidental" para designar esta realidade unitária, que envolveria Lusitanos e Galaicos, mas poderia estender-se igualmente para oriente, englobando, pelo menos parcialmente, Ástures e Vetōes ${ }^{50}$. Apontam-se, em resumo, como seus principais traços distintivos: manutenção do ${ }^{*} p$ - tanto em posição inicial (Paramaeco; Petavonius, Pintamus) como em posição intermédia (Trebopala, Toudopalandaigae), no entanto, ${ }^{*} p l->{ }^{*} \beta l$, grafado $<\mathrm{BL}>($ Bletisama); dat. do pl. em -bo, com a perda do -s; a abundância do sufixo -aiko, o qual se encontra especialmente

\footnotetext{
${ }^{46}$ Untermann 1987 67-69, Búa 1997 67-74.

${ }^{47}$ Para a análise do panorama linguístico da antiga Callaecia v. Schmoll 1959 Tovar 1983; Untermann 1992; de Hoz 1994 e 2005; Búa 1997 e 2000; Búa - Guerra 1995-2007.

${ }^{48}$ De Hoz 2005 24-35.

${ }^{49}$ Untermann 1992 372, 584-387.

${ }^{50}$ Búa 1997, 52-66
} 
documentado nas caraterísticas sequências teonímicas, cuja distribuição poderia ajudar precisamente a delimitar o território que corresponde a esta realidade cultural; a tendência para a perda da aspiração na série sonora aspirada protoindo-europeia.

Levantou-se igualmente a questão paralela da autonomia linguística dos Ástures ${ }^{51}$, em relação aos quais, no entanto, os elementos diferenciadores são ainda menos marcados que os da Galécia.

Em suma, neste universo onde a escassez de informação é patente e não há particularidades diferenciadoras marcantes é sempre difícil determinar até que ponto chegam as variaçôes linguísticas regionais.

O panorama dos nossos conhecimentos sobre as línguas pré-romanas da Hispânia revela-se, pois, muito lacunar. Os progressos que lentamente se têm concretizado, em geral impulsionados por novos documentos, e o empenho de um núcleo de investigadores permitem esperar que se vá tornando mais clara a nossa visão sobre essas línguas. Trata-se, enfim, de domínios marcados pelas incertezas e propícios a propostas ousadas, nas quais nem sempre é fácil distinguir o que apresenta alguma consistência do que é pura fantasia.

\section{Bibliografia}

\section{Abreviaturas}

MLH I, II, III, IV = Monumenta Linguarum Hispanicarum. I. Die Münzlegenden. Wiesbaden, 1975; II: Die Inschriften in iberischer Schrift aus Südfrankreich. Wiesbaden, 1980; III: Die iberischen Inschriften aus Spanien. Wiesbaden, 1990; IV: Die tartessischen, keltiberischen und lusitanischen Inschriften. Wiesbaden, 1997.

\section{Estudos}

Búa, C. (1997), "Dialectos indoeuropeos na franxa occidental hispanica" in Galicia fai dous mil anos, I. Historia. Santiago de Compostela, Museu do Pobo Galego 51-99.

(1999), "Hipótesis para algunas inscripciones rupestres del Occidente peninsular" in F. Villar, Beltrán, F., Pueblos. lenguas y escrituras en la Hispania prerromana: Actas del VII Coloquio sobre Lenguas y Culturas Paleohispánicas. Salamanca 309-327.

(2000), Estudio lingüístico de la teonimia lusitano-gallega, tesis doctoral inédita. Salamanca, Universidad de Salamanca.

(2014), "Novedades en la teonimia galaico-lusitana" in Os Celtas na Europa Atlántica. III Congreso Internacional sobre a Cultura Celta (Narón, 15-17.04.2011). Lugo 103-144.

- Guerra, A. (1995-2007), "Algunas consideraciones acerca del epígrafe del árula de Madre de Deus, Sintra” in J. C. Ribeiro, ed. Diis Deabusque: Actas do II Colóquio Internacional de Epigrafia "Culto e Sociedade". Sintra 79-96.

\footnotetext{
${ }^{51}$ De Hoz 2005 18-24.
} 
Carneiro, A. - Encarnação, J. d' - Oliveira, J. de - Teixeira, C. (2008), "Uma inscrição votiva em língua lusitana", Palaeohispanica 8 167-178.

Correa, J. A. (1985), "Consideraciones sobre las inscripciones tartesias" in de J. Hoz, ed., Actas del III Coloquio sobre Lenguas y Culturas Paleohispánicas. Salamanca 377-395.

(1989), "Posibles antropónimos en las inscripciones en escritura del SO. (o tartesia)", Veleia $6243-251$.

(1992), "La epigrafía tartesia" in D. Hertel \& J. Untermann eds., Andalusien zwischen Vorgeschichte und Mittelalter, Köln 75-114.

(1994), "La lengua ibérica", Revista Española de Lingüistica, 24 263-287.

(1996), "La epigrafía del sudoeste: estado de la cuestión" in F. Villar - Encarnação, J. d' eds, La Hispania prerromana. Actas del VI Coloquio sobre Lenguas y Culturas Prerromanas de la Península Ibérica. Salamanca 65-76.

(2005), "Del alfabeto fenicio al semisilabario paleohispánico", Acta Palaeohispanica X. Palaeohispanica 5, 137-154.

(2009a), "Reflexiones sobre la lengua de las inscripciones en escritura del sudoeste o tartesia” Acta Palaeohispanica X. Palaeohispanica 9 295-307.

(2009b), "Identidad, cultura y territorio en la Andalucía prerromana a través de la lengua y la epigrafía" in F. Wulff Alonso - M. Álvarez Martí-Aguilar eds., Identidades, culturas y territorios en la Andalucía prerromana. Sevilla - Málaga 273-295.

Correia, V. H. (1996), A epigrafia da Idade do Ferro do Sudoeste da Peninsula Ibérica. Porto, ETNOS.

Curado, F. P. (1989), "As inscriçōes indígenas de Lamas de Moledo (Castro Daire) e do Cabeço das Fráguas, Pousafoles (Sabugal)" in Actas do I Colóquio Arqueológico de Viseu, Viseu 349-370.

Fernandes, L. - Carvalho, P. S. - Figueira, N. (2009), "Divindades indígenas numa ara inédita de Viseu", Acta Palaeohispanica X =Palaeohispanica 9 143-155.

Gómez Moreno, M. (1949), Miscelaneas, Historia, Arte, Arqueologia: La antiguedad. Madrid.

Gorrochategui, J. (1984), Estudio sobre la onomástica indígena de Aquitania. Bilbao.

(2009), "Vasco antiguo: algunas cuestiones de geografía e historia lingüísticas", in F. Beltrán Lloris et alii eds, Actas del IX Coloquio sobre Lenguas y Culturas Paleohispánicas, Palaeohispanica. 10 539-555.

Hoz, J. de (1994) "Castellum Aviliobris. Los celtas del extremo Occidente continental" in R. Bielmeier - R. Stempel - R. Landsweert, eds, Indogermanica et Caucasica: Festschrift für Karl Horst Schmidt. Berlin - New York 348-362.

(1996), "El origen de las escrituras paleohispánicas quince años después", in F. Villar J. d'Encarnação, eds, La Hispania Prerromana. Actas del VI Coloquio sobre Lenguas y Culturas Prerromanas de la Península Ibérica. Salamanca 171-206.

(2001), "Hacia una tipología del ibérico" in Villar, F. - Fernández Álvarez, M. P. eds, Religión, lengua y cultura prerromanas de Hispania. Actas del VIII Coloquio sobre lenguas y culturas prerromanas de la Peninsula Ibérica. Salamanca 335-362.

(2005), "Las lenguas del Noroeste peninsular y la relación entre ástures y galaicos", Larauco 5 17-38.

(2009), "El problema de los límites de la lengua ibérica como lengua vernácula", Acta Palaeohispanica X, Palaeohispanica 9 413-433.

(2010), Historia lingüistica de la Península Ibérica, I. Preliminares y mundo meridional prerromano. Madrid.

(2011a), Historia linguiistica de la Peninsula Ibérica, II. El mundo ibérico prerromano y la indoeuropeización, Madrid.

(2011b), "Las funciones de la lengua ibérica como lengua vehicular" in C. Ruiz Darasse et E. R. Luján eds, Contacts linguistiques dans l'Occident méditerranéen antique, Madrid 27-64.

Hübner, E. (1893), Monumenta linguae Ibericae. Berlin.

Humboldt, W. von (1821), Prüfung der Untersuchungen über die Urbewohner Hispaniens vermittels der Vaskischen Sprache, Berlin: F. Dümmler (trad. esp. 1990, Los primitivos habitantes de España, Madrid: Polifemo). Jordán, C. (2004), Celtibérico. Zaragoza.

Koch, J. T. (2009), Tartessian: Celtic in the South-west at the Dawn of History. Aberystwyth, Celtic Studies Publications. 
Koch, J. T. (2011), Tartessian 2. Aberystwyth, Centre for Advanced Welsh and Celtic Studies.

Lakarra, J. (2009), "Forma canónica y cambios en la forma canónica en la prehistoria de la lengua vasca", Palaeohispanica 9 557-609.

Lakarra, J. (2010), "Haches, diptongos y otros detalles de alguna importancia: notas sobre numerales (proto) vascos y comparación vasco-ibérica (con un apéndice sobre hiri y otro sobre bat-bi)", Veleia 27 191-238.

Mitxelena, K. (1961), Fonética histórica vasca. Donostia-San Sebastián (2a ed. 1977).

Orduña, E., (2005), "Sobre algunos posibles numerales en textos ibéricos", in Beltrán Lloris, F. et alii eds., Actas del IX Coloquio sobre lenguas y culturas paleohispánicas, Palaeohispanica. 10 491-506.

Orduña, E. (2011), "Los numerales ibéricos y el proto vasco", Veleia 28 125-139.

Prósper, B. M. (2002), Lenguas y religiones prerromanas del Occidente de la Península Ibérica. Salamanca, Universidad.

Prósper, B. M. - Villar, F. (2009), "Nueva inscripción lusitana procedente de Portalegre", Emerita 72 1-32.

Quintanilla, A. (1998), Estudios de fonología ibérica, Vitoria-Gasteiz.

Ribeiro, J. C. (2010), "Algumas considerações sobre a inscrição em 'lusitano' descoberta em Arronches", Serta Palaeohispanica J. de Hoz = Palaeohispanica 1041-62.

Ribeiro, J. C. (2013), “'Damos-te esta ovelha, ó Trebopala!'a invocatio lusitana de Cabeço das Fráguas (Portugal)", Palaeohispanica 13 237-256.

Rodrigues, A. V. (1959-60), Inscrição de tipo "porcom" e aras anepígrafes do Cabeço das Fráguas (Guarda), Humanitas 11-12 71-77.

Rodríguez Ramos, J. (2002), "Las inscripciones sudlusitano-tartesias: su función, lengua y contexto socio-económico", Complutum 13 85-95.

Rodríguez Ramos, J. (2004), Análisis de epigrafía ibérica. Vitoria-Gasteiz, Instituto de Ciencias de la Antigüedad.

Tovar, A. (1961), Ancient languages from Spain and Portugal. New York.

Tovar, A. (1966-67), "L'inscription du Cabeço das Fráguas et la langue des Lusitaniens", Études Celtiques $11237-268$.

Tovar, A. (1983), "Lengua y etnia en la Galicia antigua: el problema del celtismo", in Pereira Menaut, G., ed. Estudos de cultura castrexa e de Historia Antiga de Galicia. Santiago de Compostela 247-282.

Tovar, A. (1985), "La inscripción del Cabeço das Fráguas y la lengua de los lusitanos", in Actas del III Coloquio de Lenguas e Culturas Paleohispánicas. Salamanca 227-253.

Untermann, J. (1962), "Áreas e movimentos linguísticos na Hispania pré-romana", Revista de Guimarães $725-61$

Untermann, J. (1969), “Lengua ibérica y lengua gala en la Galia Narbonensis", APL 12 99-161.

Untermann, J. (1987) "Lusitanisch, Keltiberisch, Keltisch" in Gorrochategui, J. - Melena, J. L. -Santos, J., eds. Studia Palaeohispanica. Actas del IV Coloquio sobre Lenguas y Culturas Paleohispánicas = Veleia 2-3 1985-1986 57-76.

Untermann, J. (1992), "Anotaciones al estudio de las lenguas prerromanas del Noroeste de la Península Ibérica", in Galicia: Da romanidade à xermanizació. Santiago de Compostela, 367-397.

Untermann, J. (2002) "A epigrafia em língua lusitana e a sua vertente religiosa", in Ribeiro, J. C., Religiōes da Lusitânia: Loquuntur saxa. Lisboa 67-70.

Vallejo, J. M. (2005), Antroponimia indígena de la Lusitania romana. Vitoria - Gasteiz. Universidad del País Vasco

Vallejo, J. M. (2013), "Hacia una definición de lusitano", in Acta Palaeohispanica XI. Palaeohispanica 13 273-291.

Villar, F. (2000), Indoeuropeos y no indoeuropeos en la Hispania prerromana. Salamanca, Universidad.

Villar, F. - Prósper, B. M. (2005), Vascos, Celtas e Indoeuropeos. Genes y lenguas. Salamanca, Universidad de Salamanca.

Velaza, J. (1996), Epigrafía y lengua ibéricas. Madrid, Arco Libros.

Velaza, J. (2006), "Lengua vs. cultura material: el (viejo) problema de la lengua indígena de Catalunya", in M. C. Belarte - J. Sanmartí eds, De las comunitats locals als estats arcaics, la formació de les societats complexes a la costa del Mediterrani occidental. Barcelona 3-80.

Velaza, J. (2012), "El vasco antiguo y las lenguas vecinas según la epigrafía", in I. Igartua ed., Euskara eta inguruko hizkuntzak historian zehar, Vitoria-Gasteiz, Eusko Jaurlaritza-Gobierno Vasco 75-84.

Wikander, S. (1966), "Sur la langue des inscriptions Sud-Hispaniques", Studia Linguistica 20 1-8.

Wodtko, D. S. (2010), "The problem of Lusitanian" in B. Cunliffe - J. T. Koch, Celtic from the West, Oxford, Oxbow 335-367. 